\title{
MEDIA PEMBELAJARAN PENGENALAN METAMORFOSIS SEMPURNA DAN TIDAK SEMPURNA MENGGUNAKAN AUGMENTED REALITY David Kristian Lado ${ }^{1}$, Melati Rosanensi ${ }^{2}$, INyoman Yoga Sumadewa ${ }^{3}$ \\ Fakultas Teknik dan Desain Universitas Bumigora \\ christiandavidlado@gmail.com, Melati.rn@universitasbumigora.ac.id, yoga@universitasbumigora.ac.id \\ DOI https://doi.org/10.30812/sasak.v2i1.752
}

\begin{abstract}
Abstrak
Pemanfaatan teknologi Augmented Reality (AR) sebagai media pembelajaran tentang metamorphosis sempurna dan tidak sempurna bertujuan sebagai alat bantu dalam proses belajar dan mengajar alternatif antara guru dan siswa dengan cara memvisualisasikan objek 3D secara realtime. Aplikasi multimedia pengenalan metamorphosis sempurna dan tidak sempurna ini berbasis Augmented Reality dengan mengacu materi dalam buku IPA Sekolah Dasar kelas IV (Empat) kurikulum 2013.Metodologi yang digunakan dalam pengembangan aplikasi ini adalah metode pengembangan Luther Sutopo. Dimana metode ini terdiri dari 6 (Enam) tahap yaitu concept, design, material collecting, assembly, testing, dan distribution.Hasil atau keluaran dari aplikasi yang penulis bangun ini adalah sebuah aplikasi android dengan memanfaatkan teknologi Augmented Reality untuk memperlihatkan wujud atau bentuk dari tahapan hewan yang mengalami metamorphosis sempurna dan metamorphosis tidak sempurna.Kesimpulan dari penelitian ini adalah secara keseluruhan respon dari end user terhadap aplikasi ini sudah cukup baik. Dimana dalam beberapa pertanyaan terkait aplikasi AR ini sudah memberikan hasil jawaban yang baik. Ini dibuktikan dengan beberapa pengujian yang telah penulis lakukan terhadap aplikasi dimana penguji adalah penulis dan enduser.
\end{abstract}

Kata Kunci:Augmented Reality (AR), Unity, Android, Metamorfosis Sempurna, Metamorfosis Tidak Sempurna.

\begin{abstract}
Utilization of Augmented Reality (AR) technology as a learning medium about perfect and imperfect metamorphosis aims as a tool in the alternative learning and teaching process between teachers and students by visualizing 3D objects in realtime. This multimedia application for introducing perfect and imperfect metamorphosis is based on Augmented Reality by referring to the material in the Science books for Elementary School grade IV (Four) curriculum 2013. The methodology used in developing this application is the Luther Sutopo development method. Where this method consists of 6 (Six) stages, namely concept, design, material collecting, assembly, testing, and distribution. The results or the output of the application that the author built is an android application using Augmented Reality technology to show the shape or form of the stages of animals that experience perfect metamorphosis and imperfect metamorphosis. The conclusion of this study is that the overall response of the end user to this application is quite good. Where in some questions related to this AR application has given good answers. This is evidenced by some of the tests that the authors have conducted on applications where the testers are writers and end users.
\end{abstract}

Keyword:Augmented Reality (AR), Unity, Android, Perfect Metamorphosis, Perfect Metamorphosis. 


\section{PENDAHULUAN}

Pendidikan di sekolah dasar merupakan lembaga yang dikelola dan diatur oleh pemerintah yang bergerak di bidang pendidikan yang diselenggarakan secara formal yang berlangsung selama 6 tahun dari kelas 1 sampai kelas 6 untuk anak atau siswa-siswi di seluruh indonesia tentunya dengan maksud dan tujuan yang tidak lain agar anak indonesia menjadi seorang individu yang telah diamanatkan atau yang sudah dicita- citakan dalam Undangundang Dasar 1945 [1]. Dalam pelaksanannya, pendidikan di sekolah dasar diberikan kepada siswa dengan sejumlah materi atau mata pelajaran yang harus dikuasainya. Salah satunya adalah mata pelajaran Ilmu Pengetahuan Alam (IPA).

Ilmu Pengetahuan Alam (IPA) adalah suatu ilmu yang mempelajari tentang alamsekitar beserta isinya yakni semua benda yang ada di dalam, peristiwa dan gejala-gejala yang muncul di alam [2]. Dalam mata pelajaran Ilmu Pengetahuan Alam (IPA) banyak pelajaran yang bisa dicontohkan langsung oleh alam, dan didalamnya juga ada yang berkaitan dengan makhluk hidup, salah satunya adalah metamorphosis.

Metamorfosis merupakan materi BAB IV pada mata pelajaran Ilmu Pengetahuan Alam yang ditunjukan pada siswa kelas IV (empat) sekolah dasar dan mengacu pada kurikullum 2013. Metamorfosis adalah sebuah proses perubahan secara bentuk maupun karakter dari sebuah sebuah benda yang hidup maupun mati karena mengalami proses sehingga mewujudkan suatu wujud baru dengan karakter atau sifat yang baru [2]. Untuk tahapan metamorphosis dibedakan menjadi 2 jenis yaitu metamorphosis sempurna dan metamorphosis tidak sempurna.Metamorfosis sempurna adalahmetamorfosis yang mengalami 4 tahap pertumbuhan. Tahapan tersebut, yaitu telur, larva, pupa, dan dewasa. Sedangkan Metamorfosis Tidak Sempurna adalah metamorfosis yang mengalami 3 tahappertumbuhan, yaitu telur, nimfa, dan dewasa [3]. Sebagai contoh untuk metamorphosis sempurna dan tidak sempurna yaitu pada katak dan kecoa. Adapun tahapan metamorphosis sempurna pada katak yaitu dimulai dari telur, kecebong, katak muda, dan katak dewasa. Lalu untuk tahapan metamorfosis tidak sempurna pada kecoa yaitu telur, nimfa dan kecoa dewasa.
Berdasarkan hasil wawancara penulis dengan salah satu tenaga pengajar atau guru Sekolah Dasar Katolik Santo Antonius Padua Ampenan guru masih menggunakan buku sebagai media pembelajaran, dan proses dari materi yang disampaikan oleh guru tersebut tidak dapat dilihat secara langsung oleh siswa sehingga kurang mendapat gambaran nyata tentang tahapan metamorphosis tersebut. Jika kondisi tersebut terus berlangsung dapat mengakibatkan lambatnya siswa dalam memahami materi dan memiliki pengetahuan yang sangat minim dari materi metamorphosis yang ditelah disampaikan oleh pengajar atau guru. Oleh karena itu penulis menemukan solusi dalam mempermudah guru dalam penyampaian materi dan diharapkan membuat siswa lebih antusias dalam mempelajari dan mengenal tahapan metamofosis sempurna dan tidak sempurna khususya untuk Sekolah Dasar Katolik ST Antonius dengan menggunakan teknologi Augmented Reality sebagai alat bantu dari buku atau media pembelajaran sebelumnya yang dikemas dalam aplikasi berbasisandroid.Augmented Reality (AR) adalah teknologi yang menggabungkan benda maya dua dimensi dan ataupun tiga dimensi ke dalam sebuah lingkungan nyata tiga dimensi lalu memproyeksikan benda-benda maya tersebut dalam waktu nyata. Tidak seperti realitas maya yang sepenuhnya menggantikan kenyataan namun Augmented Reality hanya menambahkan atau melengkapi kenyataan [4].

\section{METODOLOGI}

Dalam penyusunan skripsi ini, penulis menggunakan tahapan penelitian dengan metode Multimedia Development Life Cycle, untuk membangun "Media PembelajaranPengenalan Metamorfosis Sempurna dan Tidak Sempurna Menggunakan Augmented Reality" sebagai media belajar alternatif untuk siswa SDK St. Antonius Mataram berbasis mobile. Menurut (Luther sutopo, 2003), pengembangan multimedia dilakukan berdasarkan enam tahap yaitu Konsep (Concept), Perancangan (Design), Pengumpulan bahan (Material Collecting),

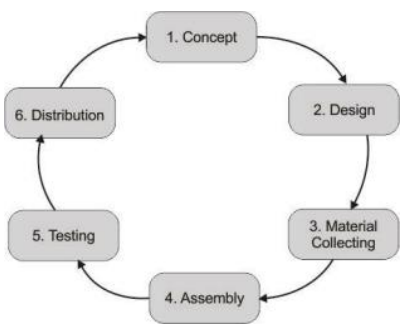


Pembuatan (Assembly), Pengujian (Testing), dan Pendistribusian(Distribution).

Gambar 1. Metode Mutimedi Development Life Cycle.

\section{A. Konsep(Concept)}

Dalam tahap ini akan ditentukan tujuan dari pembuatan aplikasi, serta mentukan siapa pengguna, tujuan dari perancangan aplikasi, dimana tujuan dari aplikasi ini adalah untuk membangun sebuah aplikasi Pengenalan Metamorofosis Sempurna dan Tidak Sempurna dengan memanfaatkan teknologi Augmented Reality yang menarik, interaktif, edukatif dan akan diterapkan pada perangkatandroid.

\section{PengumpulanData}

Pengumpulan data dilakukan untuk mendapatkan data-data valid yang nantinya dibutuhkan dalam membangun aplikasi seperti observasi, kuisioner, wawancara, dan studi literatur. Dalam penelitian ini penulis menggunakan teknik pengumpulan data diantaranya adalah:

\section{a) Observasi}

Dalam proses ini penulis melakukan pengamatan pada salah satu sekolah dasar katholik di Mataram, yaitu SDK St Antonius Mataram. Observasi sendiri merupakan teknikpengumpulandatadengancara melakukan pengamatan terhadap kegiatan yang sedang berlangsung. Observasi ini dilakukan saat dimana proses belajar mengajar sedang berlangsung, dan ditemukan bahwa proses belajar mengajar masih menggunakan cara konvensional atau masih menggunakan metode mengajar pada umumnya.

\section{b) StudiPustaka}

Dalam proses ini, penulis melakukan pengumpulan data dengan cara mencari referensi mengenai "Media Pembelajaran Pengenalan Metamorfosis Sempurna dan Tidak Sempurna Menggunakan Augmented Reality" melalui buku yang membahas tentang "Ilmu Pengetahuan Alam" serta mendownload beberapa gambar dan informasi yang berhubungan dengan aplikasi yang akandibangun.

c) Kuisioner

Dalam tahap ini penulis melakukan pengumpulan data melalui kuisioner kepada pengguna atau user sebanyak 30 narasumber yang terdiri dari guru dan siswa SDK St Antonius Mataram. Metode pengumpulan data ini dilakukan setelah semua aplikasi selesai dikerjakan dan sudah melalui tahap uji coba oleh alpha test atau pengembang, selanjutnya akan dilakukan oleh beta test atau pengguna akhir dengan cara melalui kuisioners[5].

d) Wawancara

Kegiatan wawancara dilakukan untuk mendapatkan informasi yang mendalam tentang pandangan, wawasan dan aspek kepribadian peserta didik yang diberikan secara lisan dan spontan.

\section{IdentifikasiPengguna}

Sasaran dari pembuatan "Aplikasi Multimedia Pengenalan Metamorfosis Sempurna dan Tidak Sempurna" ini adalah untuk kalangan guru SDK St Antonius Mataram dan di salurkan ke siswa-siswi SDK St Antonius Mataram, namun tidak menutup kemungkinan pengguna dapat berasal dari kalangan umum. Karakteristik yang diperlukan oleh pengguna agar bisa menggunakan aplikasi iniadalah:

a) Pengguna harus memiliki perangkat smartphone dengan versi android 5.0 (Lolipop) keatas, dan juga kamera yang mendukung untuk menjalankan aplikasi Augmented Reality.

b) Pengguna tidak memiliki keterbatasan fisik ataumental.

c) Pengguna tidak butawarna

3. Anlisis KebutuhanPerangkat

Pada tahap ini dibutuhkannya perangkat keras (hardware) dan perangkat lunak (Software) untuk membangun sebuah aplikasi Media Pembelajaran Pengenalan Tahapan Metamorfosis Sempurna dan Tidak Sempurna menggunakan Augmented Reality dengan spesifikasi berikut:

a) Perangkat Keras(Hardware)

i. Perangkat keras yang digunakan untuk membangunaplikasi:

1) PC dengan processor Amd Ryxen $32200 g \mathrm{CPU} @ 3.7 \mathrm{GHz}$

2) Memory RAM $8 \mathrm{~GB}$

3) $S D D 250 \mathrm{~GB}$

4) Video card AMD Radeon Vega 82 $G B$

5) Mouse danKeyboard

ii. Perangkat keras minimal yang bisa digunakan untuk membangunaplikasi:

1) PC atau laptop dengan Processor Intel Corei3

2) Memory RAM4GB 
3) Hardisk dengan ruang kosong 10 GB

4) Mouse danKeyboard

b) Perangkat Lunak(Software)

Perangkat Lunak yang digunakan untuk membangun aplikasi diantaranya:

1) System Operation Windows 8.164bit

2) Blender v $2.79 \mathrm{~b} 64 \mathrm{bit}$

3) Unity 2018.1.1f1 (64-bit)

4) CorelDraw $\mathrm{X} 7$

5) Adobe Photoshop cc64bit

6) Vuforia SDK untuk ARUnity

7) Android Software Deploment kit (SDK) 8) JDK1.8.1

c) Perangkat Smartphone untuk uji coba aplikasi

Smartphone yang digunakan adalah Smartphone Xiaomi Note 42017 dengan spesifikasi hardware dan software sebagai beriku:

1) Android 7.0(Marshmallow)

2) Layer5.5inc

3) CPU Octa-core $2.0 \mathrm{GHzCorte-A53}$

4) GPU Adreno506

5) RAM $3 \mathrm{~GB}$

6) Kamera $13 \mathrm{mp}$ (mega pixel)

\section{B. Perancangan(Design)}

Pada tahap Design (Perancangan) dilakukan untuk menggambarkan perancangan dari setiap scene dalam aplikasi, perancangan navigasi untuk setiap menu juga harus dibuat. Pada penelitian ini spesifikasi yang akan dibuat adalah rancangan produksi, struktur navigasi, dan desain antarmuka (interface).

\section{KontenInformasi}

Aplikasi media pembelajaran ini berisi informasi tentang metamorphosis sempurna dan tidak sempurna. Buku referensi yang digunakan penulis dalam membangun aplikasi ini adalah buku "IPA Terpadu" dari penulis (Muhammad Amien, Widya Ristanti, Ratna Dewi Kusumawati) Untuk metode penyampaian informasi akan menggunakan animasi augmented reality 3D disertai suara, danteks.

\section{RancanganProduksi}

Dalam tahapan perancangan produksi nantinya agar calon pengguna (user) bisa mendapatkan marker dan bisa mengakses aplikasi ini sesuai dengan apa yang telah kita gambarkan dalam tahapan konsep (Identifikasi
Pengguna), aplikasi ini ditujukan untuk guru yang mengajar mata pelajaran IPA, namun tidak menutup kemungkinan aplikasi ini digunakan untuk umum. Agar mempermudah bagaimana nantinya calon pengguna (user) mendapatkan marker dan mengakses aplikasi, penulis membuat 2 rancangan konsep produksi,yaitu:

\section{a) StickerMarker}

Untuk "Sticker Marker" penulis menyediakan marker yang sudah dicetak dalam bentuk sticker. Selanjutnya sticker tersebut akan ditempel dalam buku paket siswa pada materi metamorphosis.

\section{b) GoogleDrive}

Dalam konsep ini pengguna dapat secara langsung mendownload marker yang sudah penulis siapkan dan simpan ke dalam media penyimpan cloud atau google drive, setelah marker berhasil didownload pengguna bisa langsung mencetak marker sendiri. Agar calon pengguna tidak repot untuk mencari link download, penulis telah menyediakan button download yang secara otomatis mengalihkan pengguna pada link download marker tersebut.

3. StrukturNavigasi

Untuk menggambarkan hubungan antar menu dalam aplikasi yang nantinya akan dibuat. Dalam penelitian ini penulis menggunakan struktur navigasi hirarki, yang berbentuk berupa cabang-cabang. Untuk lebih jelasnya struktur navigasi hirarki dapat dilihat pada gambar dibawahini:

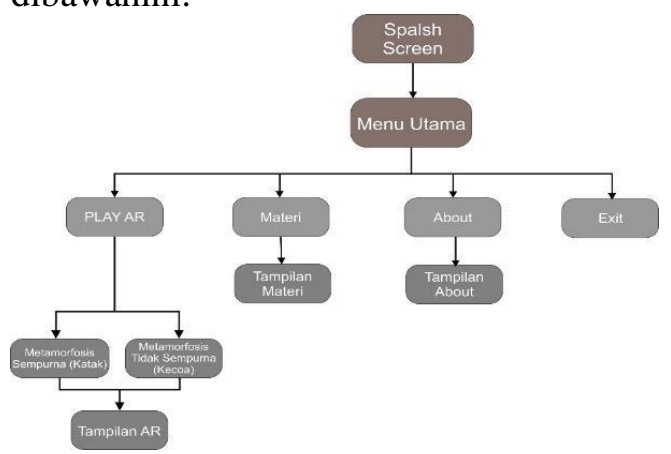

Gambar 2. Stuktur Navigasi

4. Design Antarmuka(Interface)

Untuk tampilan interface atau antarmuka dari aplikasi ini akan didesain sesederhana mungkin agar para pengguna khususnya kalangan awam tidak kesulitan dalam menggunakan atau mengoprasikan aplikasi nantinya. Berikut ini merupakan konsep dari desain antarmuka atau interface dari aplikasi yang akan dibuat: 
a) MenuUtama

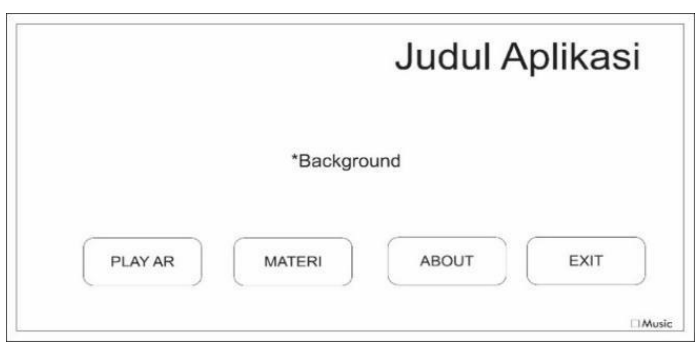

Gambar 3. Konsep Menu Utama

i. Terdapat judul aplikasi dalam konsep menu utama disertaibackground.

ii. Terdapat button "PLAY AR" yang berisi untuk navigasi ke menu"Metamorfosis Sempurna" dan "Metamorfosis TidakSempurna".

iii. Button "Materi" berfungsi untuk navigasi ke dalam menu materi mengenai metamorphosis sempurna dan tidaksempurna.

iv. Button "About" berfungsi untu navigasi ke dalam menu tentang dancara menggunakan aplikasi serta link downloadmarker.

v. Toogle "music" berfungsi untuk on off backsoundaplikasi,

vi. Button "exit" berfungsi untuk menutup aplikasi

b) Menu PLAYAR

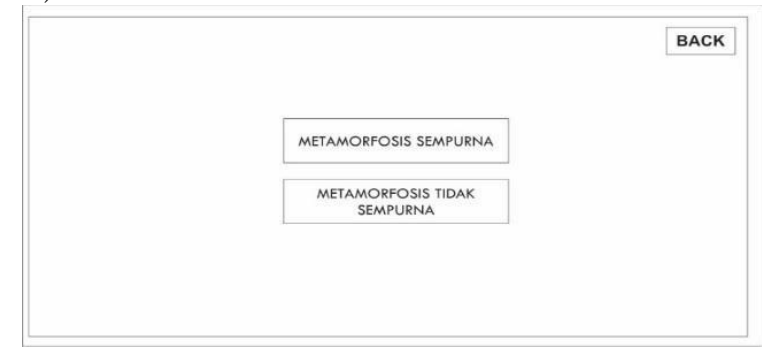

Gambar 4. Konsep Tampilan Menu PLAY AR

i. Pada tampilan "Play AR" terdapat button "Metamorfosis sempurna" dan button "metamorphosis tidak sempurna". Button tersebut untuk navigasi ke $A R$ camera untuk scan object sesuai metamorphosis yangdipilih

ii. Button "Back" berfungsi untuk kembali ke menuutama.

c) Menu MetamorfosisSempurna

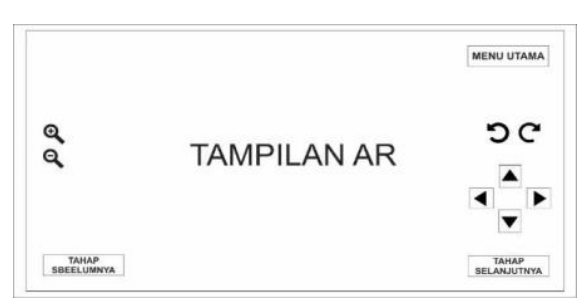

Gambar 5. Konsep Tampilan Menu Metamorfosis Sempurna

d) MenuMateri

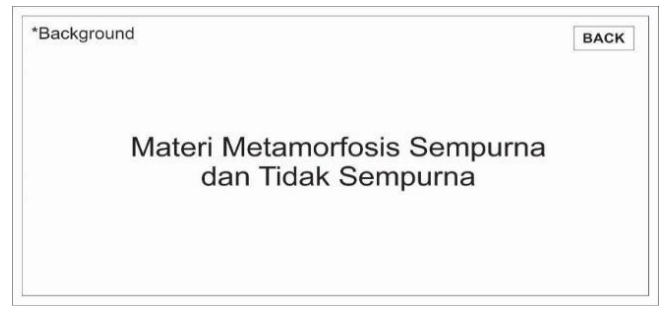

Gambar 6. Konsep Tampilan Menu Materi

i. Pada tampilan "Menu Materi" terdapat text yang berisi tentang materi Metamorfosis sempurna dan tidak sempurna yang dikutip pada Buku IPA Kelas V mengacu pada kurikulum 2013 dan sumber lainnya seperti jurnal ataue- book yang menjelesakan tentangmetamorphosis sempurna dan metamorphosis tidak sempurna.

ii. Tombol "Back" berfungsi untuk kembali ke menuutama.

e) MenuAbout

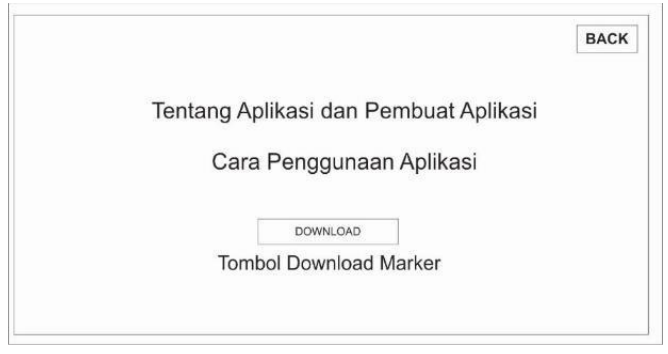

Gambar 7. Konsep Tampilan Menu About

i. Pada tampilan "About" terdapat text yang berisi tentang aplikasi augmented reality metamorphosis sempurna dan tidak sempurna dan cara penggunaan aplikasi

ii. Tombol "Back" berfungsi untuk kembali ke menuutama.

iii. Tombol "Download Marker" untuk mendownload atau mengunduh marker pada googledrive.

C. Pengumpulan Bahan (MaterialCollecting) 
Dalam tahap ini, penulis mengumpulkan bahan yang sesuai untuk kebutuhan aplikasi nantinya seperti Texture, icon, audio dan lainlain melalui internet maupun dokumentasi pribadi dari penulis.

Berikut ini merupakan bahan-bahan yang telah penulis berhasil kumpulkan dimana bahanbahan ini akan digunakan dalam proses Assembly (PembuatanAplikasi).

1. Texture

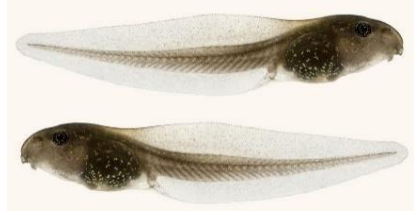

Gambar 8. Texture untuk Kecebong

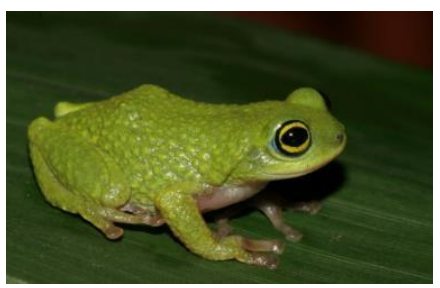

Gambar 9. Texture untuk Katak Muda

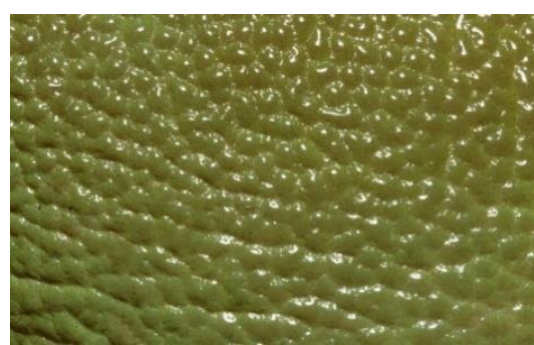

Gambar 10. Texture untuk Katak Dewasa

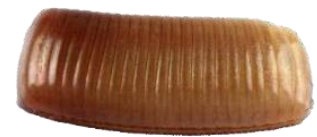

Gambar 11. Texture untuk Telur kecoa

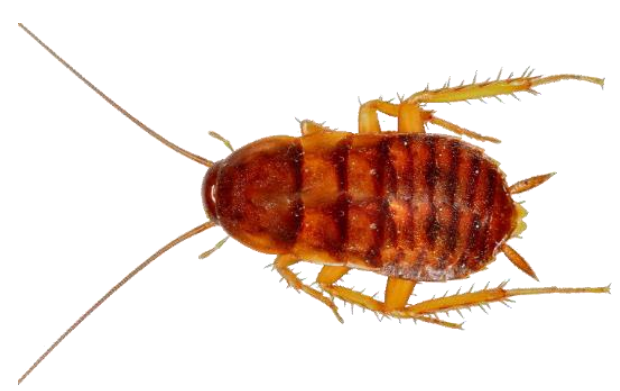

Gambar 12. Texture untuk Nimfa Kecoa

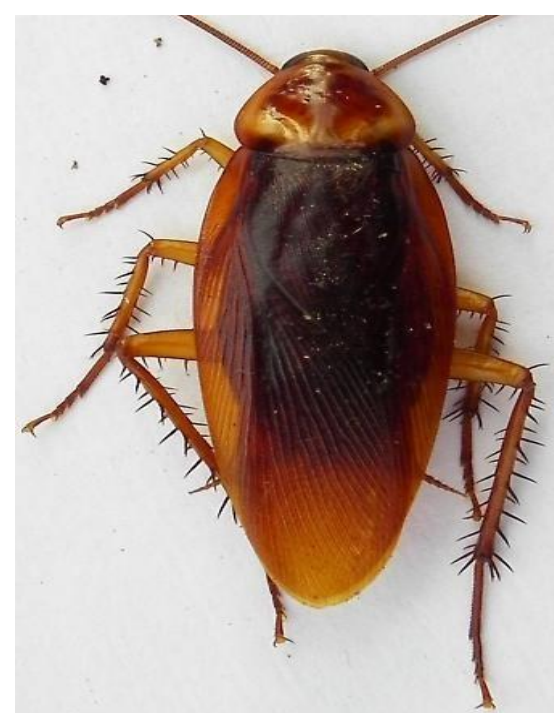

Gambar 13. Texture untuk Kecoa Dewasa

\section{Objek3D}

Objek 3 Dimensi yang nantinya akan dibuat pada aplikasi Blender:

\begin{tabular}{|c|l|}
\multicolumn{1}{|c|}{ Tabel 1. Objek 3D yang dibutuhkan } \\
\hline No & \multicolumn{1}{|c|}{ Object 3D } \\
\hline 1 & Telur Katak \\
\hline 2 & Berudu / Kecebong \\
\hline 3 & Katak Muda \\
\hline 4 & Katak Dewasa \\
\hline 5 & Telur Kecoa \\
\hline 6 & Nimfa Kecoa \\
\hline 7 & Kecoa Dewasa \\
\hline
\end{tabular}

3. Marker 


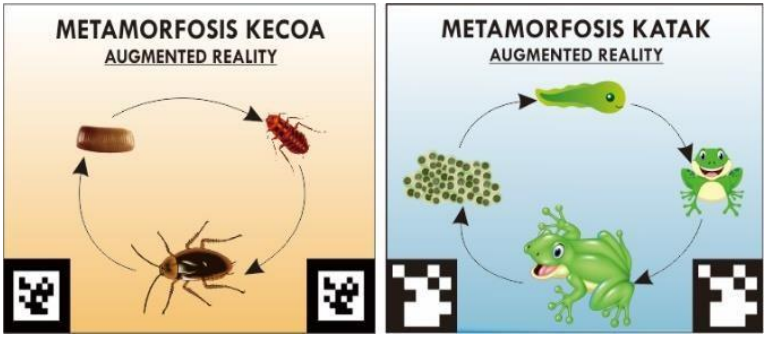

Gambar 14. Marker AR Metamorfosis Sempurna dan Tidak Sempurna

\section{Backgroundlayout}

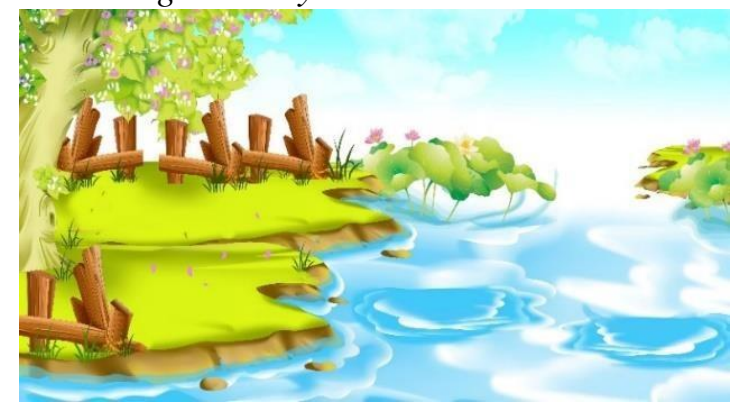

Gambar 15. Material Background Home

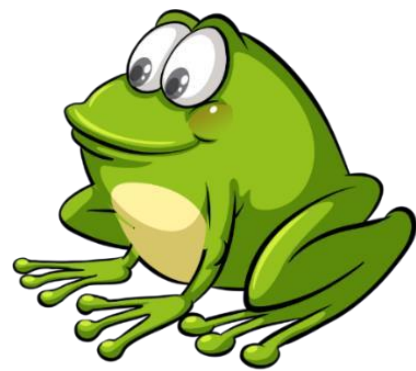

Gambar 16. Material Background Home

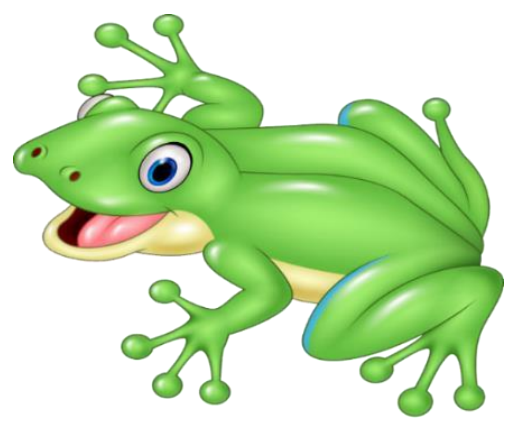

Gambar 17. Material BackgroundHome

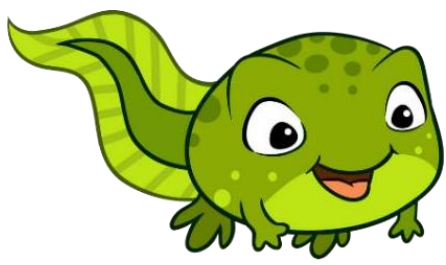

Gambar 18. Material BackgroundHome

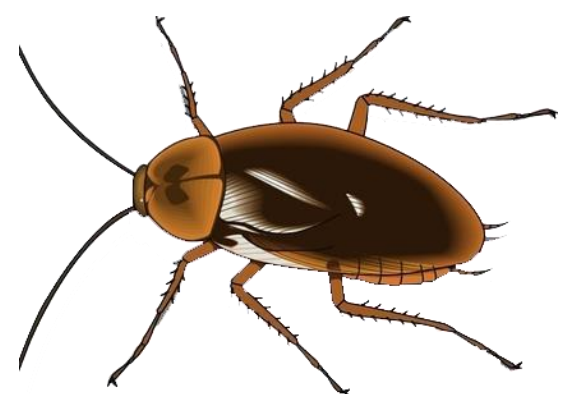

Gambar 19. Material Background Home

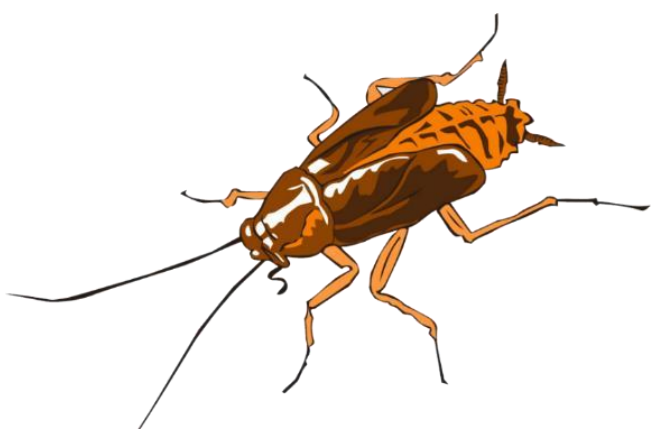

Gambar 20. Material Background Home

\section{Audio}

Beberapa Audio yang akan digunakan dalam perancangan aplikasi ini diantaranya adalah:

Tabel.2 Audio yang Dibutuhkan

\begin{tabular}{|c|c|}
\hline NO & Audio \\
\hline 1 & Button Klik \\
\hline 2 & Backsound \\
\hline
\end{tabular}

D. Pembuatan(Assembly)

Setelah semua bahan yang dibutuhkan berhasil dikumpulkan maka kita masuk kedalam tahap Pembuatan "Assembly" berdasarkan konsep yang sudah dirancang sebelumnya dan akan diImplementasikan ke dalam aplikasi. Berikut ini merupakan rincian dari tahap Pembuatan (Assembly) AR Metamorfosis Sempurna dan TidakSempurna: 
1. Tahap pertama adalah pembuatan seluruh objek 3 dimensi, 2 dimensi, animasi dan lain- lain dimana sebelumnya sudah dirancang pada tahap Material Collecting.

2. Tahap kedua adalah memasukkan asset-asset yang sudah dirancang sebelumnya ke Unity. Syarat dari Unity yang bisa digunakan harus sudah terinstal atau terdapat android SDK(Software Development Kit), JDK (Java Development Kit) serta VuforiaSDK.

3. Tahap ketiga yaitu pembuatan scene dari masing masing objek yang telah dibuatkan konsep sebelumnya, dan objek akan memiliki fungsi dengan pengkodean yang dibuat menggunakan bahasa $\mathrm{C}+$ menggunakan aplikasi Visual Studio 2017.

4. Tahap keempat yaitu pengujian debugging untuk melihat hasil dari pengkodean yang sudah dibuat apakah error atau tidak, jika tidak terdapat error maka komponenkomponen yang dibuat sudah bisa dijalankan padaUnity.

5. Proses terakhir yaitu Build aplikasi kedalam format apk dimana format ini yang nantinya dibutuhkan agar aplikasi dapat berjalan dalam sistem operasi Android.

E. Pengujian(Testing)

Dalam tahap ini akan dilakukan pengujian dengan tujuan untuk mengetahui seberapa jauh kesesuaian dari aplikasi yang telah dibuat dengan konsep yang ada, serta untuk mencari tahu kesalahan yang mungkin terdapat dalam aplikasi. Sesuai dengan metode yang digunakan yaitu Multimedia Development Life Cycle Luther Sutopo (2003), dalam proses pengujian (testing) terdapat 2 metode pengujian yaitu Alpha test dan Beta test merupakan pengujian yang dilakukan olek pembuat aplilkasi dan oleh calon pengguna yang nantinya akan menggunakan aplikasiini.

F. Pendistribusian(Distribution)

Tahap ini merupakan tahap terakhir dari tahap perancangan berdasarkan metodologi Multimedia Development Life Cycle Luther Sutopo (2003), pendistribusian dari penelitian ini dilakukan dengan cara mengunggah aplikasi ke dalam Google Drive, agar kemudian aplikasi dapat diunduh oleh para pengguna secara gratis (free) dengan cara mencari melalu link yang telah disediakan maupun dengan cara scan barcode untuk terhubung ke Google Drive. Sedangkan untuk pendistribusian marker sesuai pada dengan yang ada dalam tahap rancangan produksi dimana ada 2 konsep yaitu melalui sticker marker dan google drive.

\section{HASIL DAN PEMBAHASAN}

Pada bagian ini penulis mengulas tentang "Aplikasi Pengenalan Metamorfosis Sempurna dan Metamorfosis Tidak Sempurna menggunakan Augmented Reality" yang sudah dibuat dan siap untukdigunakan.

1. MenuUtama

Pada desain menu utama yang terdapat judul aplikasi yaitu "Augmented Reality Metamorfosis sempurna dan Metamorfosis Tidak Sempurna", di menu utama ini terdapat 4 tombol dan 1 toogle yang pertama yaitu Play $A R$ yang fungsinya adalah untuk navigasi ke menu "Metamorfosis", kedua tombol Materi, yang isinya adalah materi mengenai Metamorfosis sempurna dan tidak sempurna, ketiga yaitu tombol abou yang fungsinya menampilkan informasi tentang aplikasi dan pembuat aplikasi, lalu ada toogle music untuk menghidupkan atau mematikan backsound aplikasi, dan yang terakhir adalah tombol Exit yang berfungsi untuk keluar dari aplikasi. Untuk backgroundnya terdapat image. Berikut tampilan Menu Utama pada gambar dibawahini:

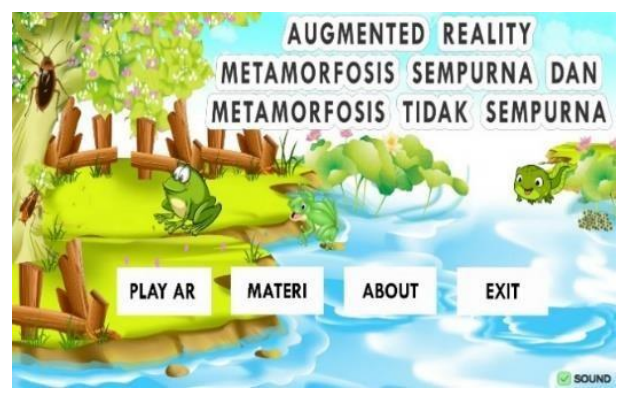

Gambar 21. Material Background Home

\section{Menu PlayAR}

Pada menu Play AR terdapat dua button yaitubutton Metamorfosis Sempurna dan button Metamorfosis Tidak Sempurna. Fungsi kedua button tersebut untuk navigasi ke AR Camera untuk scan marker dan memunculkan objek tahapan metamorphosis sesuai dengan metamorphosis yang dipilih.

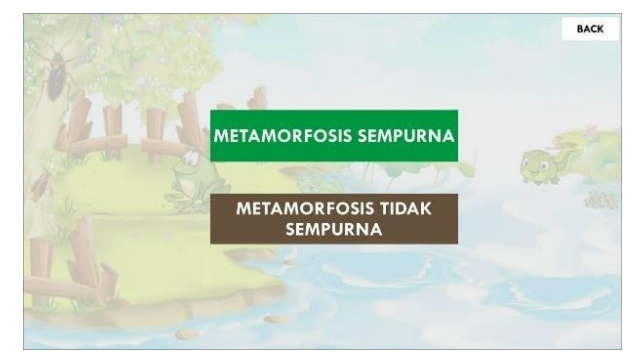

Gambar 22. Material Background Home

3. Menu MetamorfosisSempurna 
Saat masuk ke menu "Metamorfosis Sempurna" secara otomatis kamera dari smartphone akan menyala, ketika marker diarahkan ke kamera (discan) maka objek 3D akan muncul. Terdapat juga beberapa button yaitu button menu utama untuk kembali ke menu utama, lalu button zoom in zoom out objek, rotate objek, position objek, button Tahap sebelumnya dan Tahapselanjutnya.

Berikut ini merupakan tampilan Menu $A R$ Memorfosis sempurna ketika marker berhasil discan.

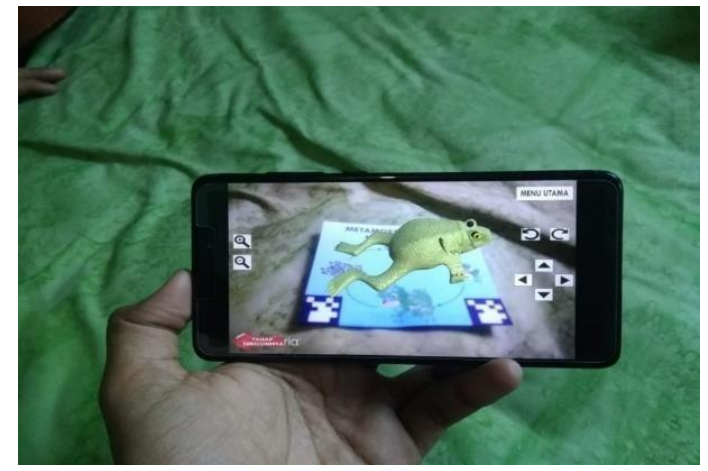

Gambar 23. Material Background Home

\section{MenuMateri}

Menu materi dibuat untuk menampilkan materi mengenai materi Metamorfosis Sempurna dan Metamorfosis Tidak Sempurna yang penulis kutip dari buku IPA SD kelas IV (Empat) kurikulum 2013. Di menu ini hanya terdapat materi singkat tentang penjelasan dan tahapan metamorphosis sempurna dan tidak sempurna, pada menu ini hanya terdapat satu button yaitu button back yang berfungsi untuk kembali ke menu utama. Berikut merupakan tampilan menu materi.

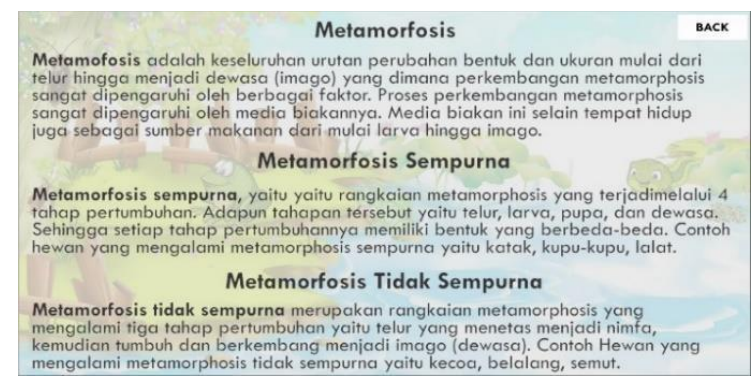

Gambar 25. Material Background Home

\section{MenuAbut}

Pada menu about terdapat informasi dari tentang aplikasi dan cara penggunaan aplikasi. pada menu ini terdapat dua tombol saja. pertama tombol Download Marker yang fungsinya adalah untuk mengalihkan user pada GoogleDrive untuk mendownload marker, dan tombol back untuk kembali ke menu utama. Berikut merupakan tampilan dari menu about.

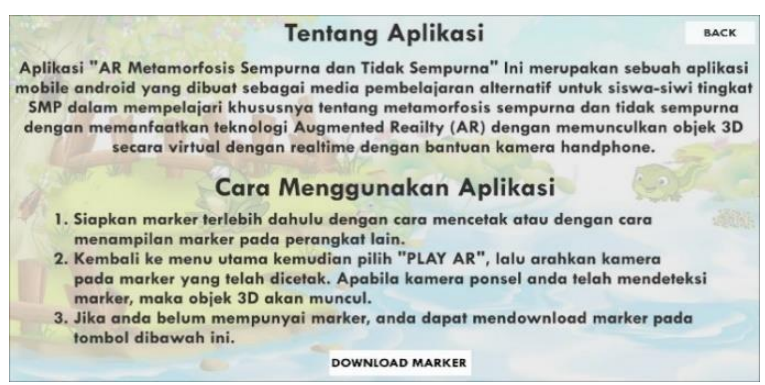

Gambar 26. Material Background Home

\section{KESIMPULAN}

A. Kesimpulan

Dari hasil penelitian dan penulisan skripsi ini, penulis dapat menarik kesimpulan sebagai berikut :

1. Pembuatan Aplikasi Media Pembelajaran Pengenalan Tahapan Metamorfosis Sempurna dan Metamorfosis TidakSempurna Menggunakan Augmented Reality berbasis mobile (Android) menggunakan Blender dan Unity3D.

2 Berdasarkan hasil Alpha Testing menggunakan versi android 7.1, aplikasi Augmented Reality yang telah dibangun dan dinyatakan dapat beroprasi dan juga menghasilkan output yang sesuai.

3. Berdasarkan hasil Beta testing yang dilakukan terhadap 27 siswa dan 3 guru, penulis dapat menarik kesimpulan sebagai berikut:

i. Desain antarmuka / Interface dari aplikasi sudah cukup baik bagi user atau pengguna.

ii. Menu-menu dan tombol Navigasi berfungsi dalamaplikasi.

iii. Model dalam konten dari aplikasi sudah mendukung.

iv. Aplikasi ini sudah cukup bermanfaat bagi pengguna karena dapat memberikan gambaran dari bentuk tahapan Metamorfosis Sempurna dan Metamorfosis Tidak Sempurna secara realtime.

v. Aplikasi sudah cukup layak untuk digunakan sebagai alat bantu atau media ajar alternatif dalam proses belajar dan mengajar di sekolah maupun dirumah.

Kesimpulan diatas penulis ambil dari kusioner dengan menghitung nilai rata-ratadari jumlah jawaban tiap responden, dimana 
disimpulkan bahwa aplikasi pengenalan metamorphosis sempurna dan tidak sempurna dapat dan memberikan informasi yang cukup bagi para responden. Karena dari hasil kueisioner, $83.89^{\circ} \%$ menyatakan sangat setuju, $16.11 \%$ menyatakan setuju, $0 \%$ menyatakan netral, $0 \%$ menyatakan tidak setuju dan $0 \%$ menyatakan sangat tidak setuju. Sehingga dapat disimpulkan bahwa aplikasi pengenalan objekobjek dari tahapan metamorphosis sempurna dan tidak sempurna ini telah sesuai dan memenuhi kebutuhan dari pegguna.

\section{B. Saran}

Dalam Skrisi ini, Penulis menyadari bahwa aplikasi ini masih jauh dari kata sempurna, oleh karena itu untuk pengembangan selanjutnya ada beberapa saran dari penulis maupun dari pengguna / user yang telah menulis sarannya pada kuisioner maupun beta test. Penulis mengambil beberapa saran yang nantinya bisa menjadi bahan pertimbangan untuk mengembangkan aplikasi Augmented Reality Metamorfosis Sempurna dan Tidak Sempurna ini menjadi lebih baik lagi. Adapun saran-saran tersebut diantaranya adalah sebagai berikut:

1. Perlu dikembangakan dengan ukuran aplikasi yang lebih kecil lagi sehingga aplikasi dapat beroperasi dengan ringan ketika dijalankan.

2. Perlu adanya proses cara untuk menanggulangi penyakit pada mata, contohnya dengan cara membuat animasi menggunakan kaca mata minus, plus dan silinder di objek mata padaaplikasi.

3. Diharapkan adanya fitur tanpa Marker sehingga objek dapat keluar tanpa harus di scan.

4. Diharapkan ada tombol volume audio pada baksounds menu utama padaaplikasi

5. Diharapkan adanya aplikasi di playstore agar mempermudah untuk mendownloadaplikasi.

Manfaat dan pengalaman yang penulis dapatkan selama kegiatan pembuatan aplikasi "Augmented Reality Metamorfosis Sempurna dan Metamorfosis Tidak Sempurna, mulai dari proses pengumpulan data tentang materimengenai metamorphosis sempurna dan metamorphosis tidak sempurna di Sekolah Dasar Katolik St Antonius Mataram, analisa tentang pentingnya sarana atau media pembelajaran (AR Maetamorfosis Sempurna dan Tidak Sempurna) dalam pendidikan, media interaktif dan effektif untuk belajar sangatlah penting untuk membangkitkan motivasi dan semangat belajar bagi siswa sekolah dasar (SD) oleh karena itu penulis membuat aplikasi "Augmented Reality Metamorfosis Sempurna dan TIdak Sempurna" karena ingin memberikan wawasan atau pandangan bahwa penggunaan mobile (Smartphone) tidak hanya digunakan untuk media sosial dan game saja, akan tetapi bisa digunakan untuk hal yang lebih bermanfaat, contohnya sebagai media belajar yang menarik dengan menggunakan teknologi Augmented Reality. Dari kesimpulan dan saran yang telah penulis buat, penulis berharap kepada temanteman yang nantinya sedang akan menyusun skripsi dapat melanjutkan ataupun mengembangkan aplikasi AR Metamorfosis Sempurna dan Tidak Sempurna ini.

\section{REFERENSI}

[1] Syofyan, H., \& Amir, T. L. (2016). PENERAPAN LITERASI SAINS DALAM PEMBELAJARAN IPA UNTUK CALON GURU SD. Jurnal Pendidikan Dasar,38.

[2] Fatimah. (2017). Meningkatkan Hasil Belajar Siswa Dalam Pembelajaran IPA Dengan Metode Demonstrasi Dikelas V SDN 10 Biau. Jurnal Kreatif Tadulako Online, 85 .

[3] Fitriyanti, D. M., \& Endrotomo. (2016). Proses Metamorfosis yang Terjadi dalam Objek Rancang Beauty Clinic Surabaya (Fasilitas Dermatologi dan Bedah Plastik). JURNAL TEKNIK POMITS, 1-2.

[4] Muntahanah, Toyib, R., \& Ansyori, M. (2017). PENERAPAN TEKNOLOGI AUGMENTED REALITY PADA KATALOG RUMAH BERBASIS ANDROID (STUDI KASUS PT. JASHANDO HAN SAPUTRA) . Jurnal Pseudocode, 83.

[5] Sugiyono, "Metode Penelitian Kuantitatif, Kualitatif dan R\&D," Bandung, 2011. 